\title{
Azygoesophageal fistula successfully treated with endoscopic injection of N-butyl-2-cyanoacrylate
}

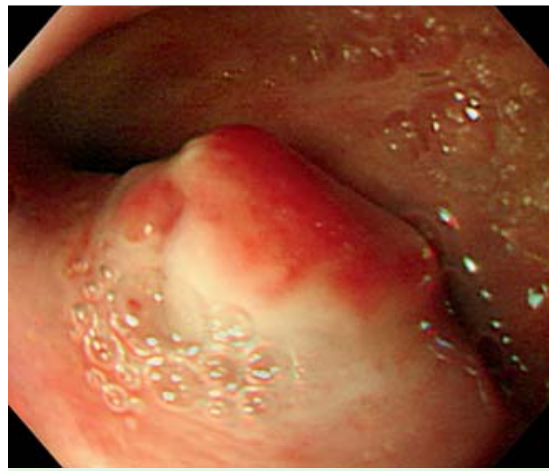

Fig. 1 A polypoid lesion with an erosive base was noted in the narrowed lumen of the mid esophagus.

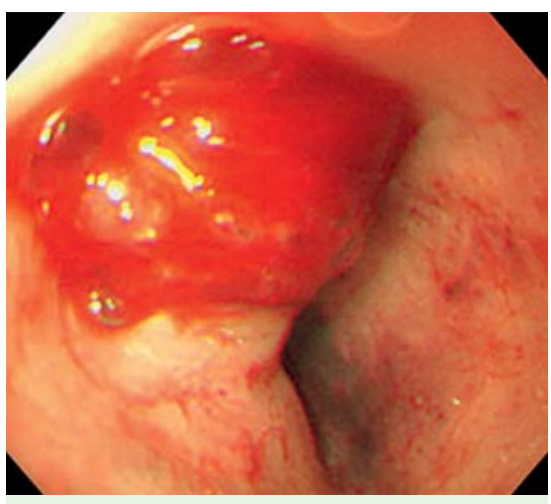

Fig. 2 Intermittent oozing of blood from the polypoid lesion was noted when it was touched by the endoscope.

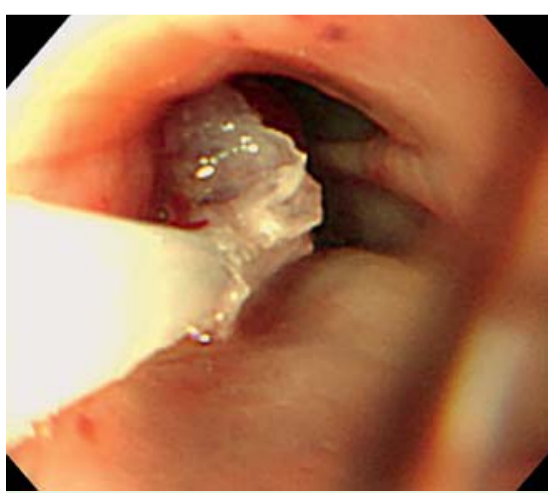

Fig. 3 N-butyl-2-cyanoacrylate and Lipiodol was injected in the erosive base. The lesion was covered with a crystal-like coating and hemostasis was achieved.

A bedridden 72-year-old man presented with massive hematemesis; esophagogastroduodenoscopy (EGD) at a local clinic revealed esophageal ulcer bleeding. After

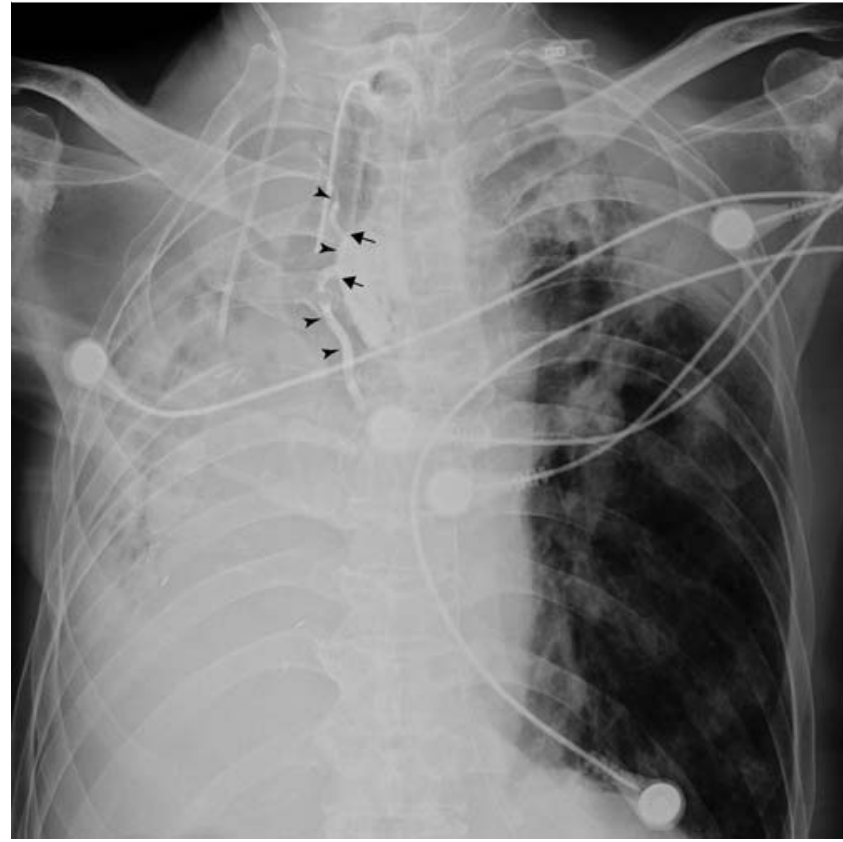

Fig. 4 One vessel (arrowheads) formed a fistula with the mid esophagus (arrows). The tip of the tracheostomy tube impacted the tortuous trachea, externally compressing the azygos vein and mid esophagus.

injection of diluted epinephrine, he was transferred to our hospital and admitted to the intensive care unit for hypovolemic shock (blood pressure, 82/47 mmHg; hemoglobin, $6.9 \mathrm{~g} / \mathrm{dL}$ ).

The patient's medical history included right pneumonectomy for pulmonary tuberculosis 8 years previously, and a tracheostomy for lung hygiene. Chest X-ray film revealed right side pneumonectomy with tube tracheostomy. The trachea was deviated to the right, and the tip of the tracheostomy tube impacted the trachea at the T3 vertebral level.

Because melena and hematochezia persisted for 2 days, we repeated EGD. One polypoid lesion with erosion and intermittent bleeding was noted in the middle esophagus, which was obviously narrowed by external compression ( Figs. 1 and 2 ).

Esophageal erosive ulcer bleeding resulting from compression by the tip of the tracheostomy tube was considered. A total $2.5 \mathrm{~mL}$ N-butyl-2-cyanoacrylate with $2.5 \mathrm{~mL}$ Lipiodol was injected into the erosion base ( Fig. 3 ).

Subsequent chest X-ray film revealed that one vessel formed a fistula with the middle esophagus ( $\bullet$ Fig. 4).

Computed tomography (CT) showed that the fistulous vessel was the azygos vein, terminating in the superior vena cava.
After endoscopic sclerotherapy, there was no recurrence of bleeding. The patient was discharged 1 month later and has had an uneventful course for the past 2 years.

Both tracheoesophageal fistula and tracheoarterial fistula are not uncommon but fatal complications after tracheostomy $[1,2]$. To the best of our knowledge, there are no reports of azygoesophageal fistula caused by compression of the tracheostomy tube. In our case, the possible pathogenesis of the azygoesophageal fistula was that the trachea was deviated due to the previous pneumonectomy, and the tip of the tracheostomy tube impacted the wall of the tortuous trachea and pushed the azygos vein towards the mid esophagus.

$\mathrm{N}$-butyl-2-cyanoacrylate is widely used not only in bleeding gastric varices but also in peptic ulcer hemorrhage or Dieulafoy lesions [3,4]. N-butyl-2-cyanoacrylate injection has been recommended as a last resort before surgery [5]. This case suggests that clinicians should pay attention to the late complications of tracheostomy, such as fistula between the trachea, esophagus, and major vessels. Furthermore, the bleeding from an azygoesophageal fistula can be defined and safely occluded by sclerotherapy with Lipiodol. 
Endoscopy_UCTN_Code_TTT_1AO_2AD

Competing interests: None

T.-Y. Shieh ${ }^{1,2}$, C.-C. Lin ${ }^{1,2}$, F.-S. Yang ${ }^{3}$, W.-H. Chang1,2, M.-J. Chen ${ }^{1,2}$

1 Division of Gastroenterology, Department of Internal Medicine, Mackay Memorial Hospital, Taipei, Taiwan

2 Mackay Medicine, Nursing and Management College, Taipei, Taiwan

3 Department of Radiology, Mackay Memorial Hospital, Taipei, Taiwan

\section{References}

1 Wood DE, Mathisen DJ. Late complications of tracheotomy. Clin Chest Med 1991; 12: 597-609

2 Jones JW, Reynolds M, Hewitt RL et al. Tracheo-innominate artery erosion: Successful surgical management of a devastating complication. Ann Surg 1976; 184: 194 - 204

3 Kurokohchi K, Maeta T, Ohgi T et al. Successful treatment of a giant exposed blood vessel in a gastric ulcer by endoscopic sclerotherapy with N-butyl-2-cyanoacrylate. Endoscopy 2007; 39: E250

4 Yoshida T, Adachi K, Tanioka Y et al. Dieulafoy's lesion of the esophagus correctly diagnosed and successfully treated by the endoscopic injection of N-butyl-2-cyanoacrylate. Endoscopy 2004; 36: 183-185

5 Lee KJ, Kim JH, Hahm KB et al. Randomized trial of N-butyl-2-cyanoacrylate compared with injection of hypertonic saline-epinephrine in the endoscopic treatment of bleeding peptic ulcers. Endoscopy 2000; 32: $505-511$
Bibliography

DOI $10.1055 / \mathrm{s}-0030-1256270$

Endoscopy 2011; 43: E168 -E169

(c) Georg Thieme Verlag KG Stuttgart · New York . ISSN 0013-726X

\section{Corresponding author}

\section{M.-J. Chen, MD}

Division of Gastroenterology

Department of Internal Medicine

Mackay Memorial Hospital

92, Section 2, Chungshan North Road

Taipei

Taiwan

Fax: +886-2-25433642

mingjen.ch@msa.hinet.net 